\title{
COMPARATIVE ANALYSIS OF ASSOCIATION AND DISPERSION CROSSES TO DETECT LINKAGE AND EPISTATIC COMPONENTS OF VARIATION
}

\author{
H. S. POONI and J. L. JINKS \\ Department of Genetics, University of Birmingham, Birmingham B15 2TT. U.K.
}

Received 28.v.82

\begin{abstract}
SUMMARY
In theory, a matched pair of crosses in which the pure breeding parents display association and dispersion for the same alleles at the same loci provides sensitive tests for the presence of complex sources of variation. Thus comparison of the genetical component of variation within the $F_{2}$ and first backcross families of such a pair of crosses can detect and distinguish between non-allelic interaction, a linkage disequilibrium of non-interacting genes and a linkage disequilibrium of interacting genes.

These theoretical expectations are confirmed by analyses of two sets of matched association and dispersion pairs of crosses involving pure breeding varieties 1 and 5 , and 2 and 12 of Nicotiana rustica and pure breeding selections for final height extracted from crosses between them by single seed descent. Furthermore, these analyses show that comparison of the genetical components of the variation within $F_{2}, B_{1}$ and $B_{2}$ families of matched association and dispersion crosses are more sensitive to non-allelic interaction and linkage disequilibrium than much larger and more complex experiments based on a single cross and analysed by conventional model fitting procedures.
\end{abstract}

\section{INTRODUCTION}

Although the means of the parents, $P_{1}$ and $P_{2}$ and of the first backcrosses, $\mathrm{B}_{1}$ and $\mathrm{B}_{2}$ are dependent on whether the genes are associated $\left(r_{d}>0\right)$ or dispersed $\left(r_{d}=0\right)$ in the parents, the $\mathrm{F}_{1}$ mean, the $\mathrm{F}_{2}$ mean and the heritable variation within $\mathrm{F}_{2}$ families $\left(V_{1 F 2}\right)$ and first backcross families after summing $\left(V_{1 B 1}+V_{1 B 2}\right)$ are not (Mather, 1949). This is still true for the $F_{1}$ mean and the $F_{2}$ mean and variance in the presence of non-allelic interaction (Mather and Jinks, 1971). If, however, the association and dispersion lead to linkage disequilibrium in the segregating generations, in the former because of an excess of coupling linkages and in the latter because of an excess of repulsion linkages, $V_{1 F 2}$ and $\left(V_{1 B 1}+V_{1 B 2}\right)$ will differ between the two kinds of crosses even in the absence of non-allelic interaction. Both $V_{1 F 2}$ and $\left(V_{1 B 1}+V_{1 B 2}\right)$ will then be greater for the association than for the dispersion cross (Mather and Jinks, 1971).

Although these relationships are well established in theory only recently have crosses become available in which the two pairs of parents display association and dispersion for the same alleles at the same loci (Jayasekara and Jinks, 1976; Pooni and Jinks, 1981). Furthermore, the joint effects of linkage and non-allelic interaction have been theoretically explored and demonstrated in practice only in respect of family means (Jinks and Perkins, 1969; Jinks, 1978). In this paper we extend these theoretical expectations to the variances, and analyse data from the two sets of association and dispersion crosses between pure breeding lines of Nicotiana rustica 
previously reported, to show how they may be used to detect nonallelic interaction and a linkage component of variation and to distinguish between them.

\section{THEORY AND METHOD}

We shall illustrate the theory with two loci each with two alleles $A, a$; $B, b$. The associated pair of pure breeding parents are then $\mathrm{P}_{1} A A B B$ and $\mathrm{P}_{2} a a b b$, while the corresponding dispersed pair are $\mathrm{P}_{1} A A b b$ and $\mathrm{P}_{2} a a B B$. In table 1 are summarised the expectations for $V_{1 F 2}$ and $\left(V_{1 B 1}+V_{1 B 2}\right)$ for the association and the dispersion crosses for four situations:

1. Linkage equilibrium and no non-allelic interaction (Mather 1949)

2. Linkage disequilibrium and no non-allelic interaction (Mather 1949)

3. Linkage equilibrium and non-allelic interaction (Mather 1967, Mather and Jinks 1971)

and

4. Linkage disequilibrium and non-allelic interaction derived by the authors.

By comparing the corresponding variances of the association and dispersion crosses we can recognise the following relationships:

(i) $V_{1 F 2}$ and $\left(V_{1 B 1}+V_{1 B 2}\right)$ do not differ between the association and dispersion crosses, in which case neither a linkage disequilibrium nor non-allelic interaction is making a significant contribution.

(ii) $V_{1 F 2}$ does not differ but $\left(V_{1 B 1}+V_{1 B 2}\right)$ does differ between the association and dispersion crosses, in which case non-allelic interaction is making a significant contribution but there is no evidence of a linkage disequilibrium.

(iii) Both $V_{1 F 2}$ and $\left(V_{1 B 1}+V_{1 B 2}\right)$ differ between the association and dispersion crosses in which case there is a linkage disequilibrium. If both $V_{1 F 2}$ and $\left(V_{1 B 1}+V_{1 B 2}\right)$ are greater for the association cross than for the dispersion cross and by an equal amount, there is no evidence for an involvement of non-allelic interaction. If, however, for one or both variances the association cross is smaller than the dispersion cross or $V_{1 F 2}$ and $\left(V_{1 B 1}+V_{1 B 2}\right)$ differ by unequal amounts there is evidence for the presence of non-allelic interaction also.

In theory, therefore, we can distinguish between all four situations in table 1 simply by comparing the heritable components of $V_{1 F 2}$ and $\left(V_{1 B 1}+\right.$ $V_{1 B 2}$ ) from corresponding association and dispersion crosses. Potentially it is a powerful experimental design that can in theory separate contributions to variation that much more complex experimental designs have failed to resolve unambiguously (Opsahl, 1956; Perkins and Jinks, 1970; Mather and Jinks, 1971, 1982). Furthermore, with the growing availability of large random samples of pure breeding lines extracted from crosses by single seed descent or dihaploidy the opportunities for using the design are now becoming available.

Where non-allelic interactions have a net directional effect they can be detected by very sensitive tests applied to the family means of the basic generations (Jinks, 1956; Jinks and Jones, 1958, Mather and Jinks, 1971). Linkage disequilbrium, however, can only be detected by an analysis of means if they involve interacting genes which are themselves making a net directional contribution and their detection requires in addition to those 
DETECTION OF LINKAGE AND EPISTATIS

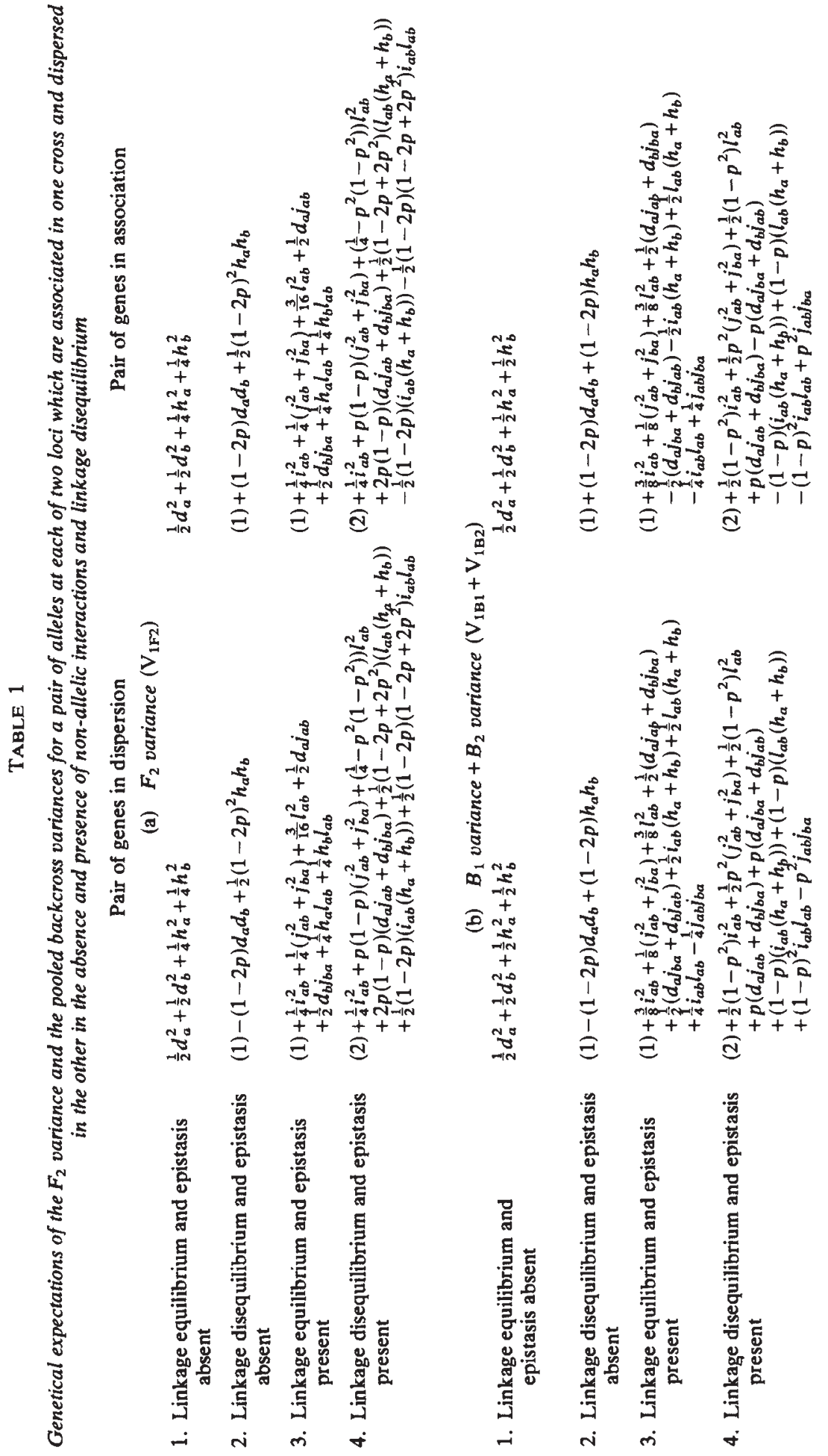


of the basic generations the means of the families of a triple test cross (Jinks and Perkins, 1969; Jinks, 1978). Analyses of means are, therefore, no substitute for an analysis of the variances for detecting non-allelic interaction and linkage contributions to variation. Nevertheless we shall apply the relevant tests to the family means, some of which have already been published, to guide us in the interpretation of the tests on the variances.

\section{EXPERIMENTAL DATA}

The data come from two sets of association and dispersion crosses. The first set includes the $P_{1}, P_{2}, F_{1}, F_{2}, B_{1}$ and $B_{2}$ families of the cross between varieties V1 and V5 of Nicotiana rustica and between two of the $\mathrm{B}$ inbred lines B2 and B35. The allelic differences for final plant height and flowering time are largely dispersed between V1 and V5 while B2 and B35 are the tallest and shortest among a random sample of 82 highly inbred lines derived by single seed descent from the $F_{2}$ of the V1 1 V 5 cross; while they are not the latest and earliest flowering of these 82 lines they are more extreme than V1 and V5 (Jinks and Perkins, 1972). B2 and B35 should, therefore, differ for the same alleles at the same loci as V1 and V5 but these alleles should now be strongly associated for final height and relatively more associated for flowering time. The degrees of association-dispersion $\left(r_{d}\right)$ for these pairs of parents for the two characters as estimated from their average phenotypes over 15 environments by the method of Jayasekara and Jinks (1976) are as follows:

$\begin{array}{lcc} & \text { V1 } \times \text { V5 } & \text { B2 } \times \text { B35 } \\ \text { Final height } & 0.26 & 1.00 \\ \text { Flowering time } & 0.13 & 0.54\end{array}$

One thousand individually randomised plants were raised for each of the two crosses in 1973 as part of an experiment which also included a triple test cross of the $82 \mathrm{~B}$ inbred lines using V1, V5 and their $F_{1}$ as the testers. The design used was that of Jinks and Perkins (1969) for equalising the amounts of information about the family means. Further details are given by Jayasekara and Jinks (1976) and Pooni et al (1978). The success of this design in equalising the standard errors of the family means can be seen in table 2 where they are listed. The corresponding within family variances are given in table 3 .

The second set of families of the basic generations comes from the cross between pure breeding varieties V2 and V12 and between the D inbreds $\mathrm{D} 10$ and D17. The cross of V2 and V12 displays a high level of non-allelic interaction and produces the most heterotic $F_{1}$ (Jinks, 1954; Jinks and Jones, 1958). The inbred lines $\mathrm{D} 10$ and $\mathrm{D} 17$ are again the extreme phenotypes among a random sample of 60 derived from the $F_{2}$ of the V $2 \times$ V 12 cross by single seed descent (Jinks, Jayasekara and Boughey, 1977). The $r_{d}$ values for final height and flowering time between these two pairs of parents based on their average phenotypes over 14 environments are as follows:

$\begin{array}{lcc} & \text { V2 } \times \text { V12 } & \text { D } 10 \times \mathrm{D} 17 \\ \text { Final height } & 0.35 & 1.00 \\ \text { Flowering time } & 0.52 & 0.77\end{array}$


TABLE 2

Family means and standard errors of the basic generations derived from the two sets of dispersion and association crosses V1 $V$ V5, B2 $\times B 35 ; V 2 \times V 12$ and D10 $D 17$ for final height and flowering time

\begin{tabular}{|c|c|c|c|c|}
\hline Generation & $\mathrm{V} 1 \times \mathrm{V} 5$ & $\mathrm{~B} 2 \times \mathrm{B} 35$ & $\mathrm{~V} 2 \times \mathrm{V} 12$ & $\mathrm{D} 10 \times \mathrm{D} 17$ \\
\hline \multicolumn{5}{|c|}{ Final height } \\
\hline $\begin{array}{l}P_{1} \\
P_{2} \\
F_{1} \\
F_{2} \\
B_{1} \\
B_{2}\end{array}$ & $\begin{array}{l}127 \cdot 34 \pm 2 \cdot 09 \\
103 \cdot 17 \pm 1 \cdot 27 \\
130 \cdot 24 \pm 1 \cdot 81 \\
126 \cdot 50 \pm 1 \cdot 50 \\
132 \cdot 30 \pm 1 \cdot 63 \\
118 \cdot 19 \pm 1 \cdot 70\end{array}$ & $\begin{array}{r}143 \cdot 84 \pm 1 \cdot 88 \\
92 \cdot 27 \pm 2 \cdot 12 \\
126 \cdot 29 \pm 1 \cdot 74 \\
124 \cdot 89 \pm 1 \cdot 52 \\
138 \cdot 61 \pm 1 \cdot 88 \\
111 \cdot 05 \pm 1 \cdot 57\end{array}$ & $\begin{array}{r}118 \cdot 43 \pm 2 \cdot 12 \\
86 \cdot 56 \pm 2 \cdot 13 \\
140 \cdot 27 \pm 1 \cdot 93 \\
124 \cdot 45 \pm 1 \cdot 25 \\
127 \cdot 07 \pm 1 \cdot 35 \\
120 \cdot 30 \pm 2 \cdot 30\end{array}$ & $\begin{array}{r}160 \cdot 33 \pm 1 \cdot 30 \\
75 \cdot 90 \pm 2 \cdot 05 \\
138 \cdot 38 \pm 1 \cdot 84 \\
126 \cdot 53 \pm 1 \cdot 07 \\
160 \cdot 19 \pm 0.93 \\
105 \cdot 91 \pm 1 \cdot 88\end{array}$ \\
\hline \multicolumn{5}{|c|}{ Flowering time } \\
\hline $\begin{array}{l}\mathbf{P}_{1} \\
\mathbf{P}_{2} \\
\mathrm{~F}_{1} \\
\mathrm{~F}_{2} \\
\mathbf{B}_{1} \\
\mathbf{B}_{2}\end{array}$ & $\begin{array}{l}77.26 \pm 0.65 \\
72 \cdot 18 \pm 0.61 \\
73.68 \pm 0.57 \\
76.13 \pm 0.58 \\
77.25 \pm 0.59 \\
73.60 \pm 0.60\end{array}$ & $\begin{array}{l}83 \cdot 65 \pm 0.70 \\
69 \cdot 84 \pm 0.76 \\
73 \cdot 83 \pm 0.57 \\
76.60 \pm 0.53 \\
80.16 \pm 0.70 \\
73.41 \pm 0.49\end{array}$ & $\begin{array}{l}91 \cdot 33 \pm 1 \cdot 42 \\
75 \cdot 05 \pm 0 \cdot 66 \\
78 \cdot 78 \pm 0.42 \\
82 \cdot 53 \pm 0.43 \\
85 \cdot 75 \pm 0.30 \\
76 \cdot 55 \pm 0.81\end{array}$ & $\begin{array}{l}97 \cdot 12 \pm 0.43 \\
73 \cdot 90 \pm 0.30 \\
79 \cdot 59 \pm 0.44 \\
81 \cdot 31 \pm 0.31 \\
92 \cdot 47 \pm 0.38 \\
77 \cdot 35 \pm 0.42\end{array}$ \\
\hline
\end{tabular}

TABLE 3

Within family variances and their degrees of freedom for the basic generations derived from the crosses V1 $\times V 5, B 2 \times B 35 ; V 2 \times V 12$ and D10 $\times D 17$ for final height and flowering time

\begin{tabular}{|c|c|c|c|c|c|c|c|c|}
\hline \multirow[b]{2}{*}{ Generation } & \multicolumn{2}{|c|}{$\mathrm{V} 1 \times \mathrm{V} 5$} & \multicolumn{2}{|c|}{$\mathrm{B} 2 \times \mathrm{B} 35$} & \multicolumn{2}{|c|}{$\mathrm{V} 2 \times \mathrm{V} 12$} & \multicolumn{2}{|c|}{ D10×D17 } \\
\hline & Variance & df & Variance & df & Variance & df & Variance & df \\
\hline \multicolumn{9}{|c|}{ Final height } \\
\hline $\mathbf{P}_{1}$ & $302 \cdot 82$ & 137 & 347.09 & 194 & $90 \cdot 32$ & 19 & $164 \cdot 95$ & 96 \\
\hline$P_{2}$ & $96 \cdot 03$ & 117 & 134.98 & 58 & $85 \cdot 56$ & 18 & $83 \cdot 81$ & 19 \\
\hline$F_{1}$ & $228 \cdot 30$ & 136 & $209 \cdot 64$ & 136 & $224 \cdot 43$ & 58 & 270.69 & 78 \\
\hline$F_{2}$ & $267 \cdot 04$ & 229 & $275 \cdot 19$ & 230 & $564 \cdot 04$ & 355 & $452 \cdot 36$ & 394 \\
\hline $\mathrm{B}_{1}$ & $266 \cdot 02$ & 190 & $278 \cdot 08$ & 150 & $291 \cdot 31$ & 153 & $207 \cdot 44$ & 235 \\
\hline $\mathrm{B}_{2}$ & $229 \cdot 78$ & 152 & $246 \cdot 71$ & 191 & $471 \cdot 91$ & 373 & $279 \cdot 72$ & 153 \\
\hline \multicolumn{9}{|c|}{ Flowering time } \\
\hline$P_{1}$ & $29 \cdot 81$ & 138 & $48 \cdot 19$ & 194 & $38 \cdot 15$ & 18 & $17 \cdot 86$ & 96 \\
\hline $\mathbf{P}_{2}$ & $22 \cdot 04$ & 118 & $17 \cdot 36$ & 58 & $8 \cdot 68$ & 19 & $1 \cdot 83$ & 19 \\
\hline$F_{1}$ & $22 \cdot 93$ & 136 & $23 \cdot 03$ & 136 & $10 \cdot 54$ & 58 & $15 \cdot 31$ & 78 \\
\hline$F_{2}$ & $40 \cdot 19$ & 232 & $33 \cdot 28$ & 231 & $65 \cdot 33$ & 355 & 38.79 & 394 \\
\hline $\mathrm{B}_{3}$ & $34 \cdot 41$ & 192 & $38 \cdot 38$ & 149 & $63 \cdot 31$ & 373 & 33.62 & 235 \\
\hline$B_{2}$ & $28 \cdot 71$ & 152 & $24 \cdot 03$ & 191 & $14 \cdot 47$ & 153 & $27 \cdot 90$ & 153 \\
\hline
\end{tabular}

Again one thousand individually randomised plants of the basic generations were raised for each cross in 1975. The experiment also included two triple test crosses of $60 \mathrm{D}$ inbred lines using V2, V12 and their $\mathrm{F}_{1}$ and $\mathrm{D} 10, \mathrm{D} 17$ and their $\mathrm{F}_{1}$ as the two sets of testers. Further details are given by Pooni and Jinks (1981). The family means and standard errors of the basic generations are given in table 2 and the corresponding within family variances in table 3 .

\section{Results}

\section{(i) Family means}

We shall begin by analysing the family means to identify the likely level of complexity of the genetical control. Models have been fitted to the 
combined family means of the basic generations of the V1 $\times \mathrm{V} 5$ and $\mathrm{B} 2 \times$ B35 pair of crosses and of the V2 $\times$ V12 and D10 $\times$ D17 pair of crosses (table 2) using the procedures of Jayasekara and Jinks (1976) to take account of the differing levels of association and dispersion in the parents of the pair of crosses in each set. This is achieved by allowing [ $d],[i]$ and $[j]$ to differ between the pair of crosses in each set while keeping $m,[h]$ and $[l]$ the same. The full digenic non-allelic interaction model, therefore, contains nine parameters for fitting to 12 family means (tables 2 and 4). Hence, weighted least squares procedures can be used to estimate the parameters and to test the goodness of fit of the model. By elimination of non-significant parameters and the inclusion of additional parameters, if the model fails the test of goodness of fit, we obtain the simplest adequate models listed in table 4 . These are the genetically simplest models that give a non-significant $\chi^{2}$ for the test of goodness of fit and in which all the estimates of the parameters are significant.

TABLE 4

Estimates of the parameters in the simplest adequate model $\left(\chi_{(n-p)}^{2}\right.$ non significant) in which every parameter is significant, for the twelve family means, six derived from the dispersion cross between pure breeding varieties and six from the corresponding association cross between extreme inbreds

\begin{tabular}{|c|c|c|c|c|}
\hline \multirow[b]{2}{*}{$\begin{array}{l}\text { Para- } \\
\text { meter }\end{array}$} & \multicolumn{2}{|c|}{$\mathrm{V} 1 \times \mathrm{V} 5$ and $\mathrm{B} 2 \times \mathrm{B} 35$ crosses } & \multicolumn{2}{|c|}{$\mathrm{V} 2 \times \mathrm{V} 12$ and $\mathrm{D} 10 \times \mathrm{D} 17$ crosses } \\
\hline & Final height & Flowering time & Final height & Flowering time \\
\hline $\begin{array}{l}m \\
{[d]_{1}} \\
{[d]_{2}} \\
{[h]^{2}}\end{array}$ & $\begin{array}{r}117 \cdot 68 \pm 0 \cdot 81^{* * *} \\
13 \cdot 37 \pm 1 \cdot 03^{* * *} \\
26 \cdot 30 \pm 1 \cdot 22^{* * *} \\
12 \cdot 70 \pm 1 \cdot 51^{* * *}\end{array}$ & $\begin{array}{r}74 \cdot 67 \pm 0.44^{* * *} \\
2.77 \pm 0.39^{* * *} \\
6 \cdot 81 \pm 0.44^{* * *} \\
6.41 \pm 1.56^{* * *}\end{array}$ & $\begin{array}{r}102 \cdot 02 \pm 1 \cdot 48^{* * *} \\
15 \cdot 93 \pm 1 \cdot 50^{* * *} \\
42 \cdot 08 \pm 1 \cdot 21^{* * *} \\
59 \cdot 27 \pm 5 \cdot 72^{* * *}\end{array}$ & $\begin{aligned} 83.25 & \pm 0.34^{* * *} \\
8.70 & \pm 0.70^{* * *} \\
11.44 & \pm 0.66^{* * *} \\
& -\end{aligned}$ \\
\hline$[i]_{1}$ & - & - & - & - \\
\hline$[i]_{2}$ & - & $2 \cdot 15 \pm 0 \cdot 64^{* * *}$ & $16 \cdot 41 \pm 1 \cdot 88^{* * *}$ & $2 \cdot 52 \pm 0 \cdot 77^{* * *}$ \\
\hline$[j]_{1}$ & - & - & $-20 \cdot 62 \pm 9 \cdot 38^{* *}$ & - \\
\hline$[j]_{2}$ & - & - & $26 \cdot 71 \pm 7 \cdot 54^{* * *}$ & $7 \cdot 72 \pm 2 \cdot 15^{* * *}$ \\
\hline$[l]$ & - & $-7 \cdot 33 \pm 1 \cdot 45^{* * *}$ & $-22 \cdot 01 \pm 5 \cdot 32^{* * *}$ & $-3.97 \pm 0.67^{* * *}$ \\
\hline$[p i]$ & - & - & - & $3 \cdot 17 \pm 0 \cdot 70^{* * *}$ \\
\hline$\chi^{2}(n-p)$ & $14 \cdot 43(8)^{\mathrm{NS}}$ & $9 \cdot 20(6)^{\mathrm{NS}}$ & $5 \cdot 09(4)^{N S}$ & $10 \cdot 29(5)^{\mathrm{NS}}$ \\
\hline
\end{tabular}

The estimates of $[d],[i]$ and $[j]$ show the expected effects of the different levels of association and dispersion between the pair of crosses of each set in that $[d]_{1}<[d]_{2},[i]_{1}<[i]_{2}$ and $[j]_{1}<[j]_{2}$. Furthermore, the adequate models all contain a single $m,[h]$ and $[l]$, that is, $m_{1}=m_{2},[h]_{1}=[h]_{2}$ and $[l]_{1}=[l]_{2}$ thus confirming that the parents of the association and of the dispersion cross of each set differ only in the way the same allelic differences at the same loci are distributed between them. Otherwise, the outcome of the model fitting confirms that a simple additive dominance model is sufficient for final height in V1 $\times$ V5 and $\mathrm{B} 2 \times \mathrm{B} 35$ whereas there are non-allelic interactions for flowering time in the same crosses and for final height and flowering time in the V2 $\times$ V12 and D10 $\times$ D 17 crosses (Jayasekara and Jinks, 1976; Pooni and Jinks, 1981). The only evidence for linkage comes from the significant [pi] parameter for flowering time in the V2 $\times$ V12 and D10 $\times$ D 17 crosses (Jinks and Perkins, 1969).

The more specific tests for a linkage disequilibrium involving interacting genes which are based upon comparisons of $B_{1}, B_{2}$ and $F_{2}$ family means 
with the corresponding $\mathrm{L}_{1}, \mathrm{~L}_{2}$ and $\mathrm{L}_{3}$ family means of the triple test cross (Jinks, 1978) are summarised in table 5. For the first set these comparisons are confined to the V1 $\times$ V 5 cross but for the second set they are available for both the V $2 \times V 12$ and D $10 \times D 17$ crosses (see section 3 ). For the $\overline{\mathrm{F}}_{2}=\overline{\mathrm{L}}_{3}$ comparison the V2 $\times \mathrm{V} 12$ and D10 $\times \mathrm{D} 17$ crosses have been combined into a single one way analysis of variance as all family means are expected to be equal in the absence of a linkage disequilibrium of interacting genes. Similarly the $\mathrm{F}_{2}$ families of the V1 $\times \mathrm{V} 5$ and $\mathrm{B} 2 \times \mathrm{B} 35$ crosses and the $\mathrm{L}_{3}$ family of the V1 1 V5 triple test cross have been combined into a single test (table 5).

\section{TABLE 5}

Tests of linkage between the genes displaying non-allelic interactions as obtained by comparing the family means of $B_{1}, B_{2}$, and $F_{2}$ generations of various crosses with the respective $L_{1}, L_{2}$ and $L_{3}$ means of the corresponding triple test crosses

Test of linkage

1. $B_{1}(V 1 \times V 5)$ vs. $L_{1}(V 1 \times V 5)$

2. $B_{2}(V 1 \times V 5)$ vs. $L_{2}(V 1 \times V 5)$

3. $F_{2}(V 1 \times V 5)$ vs. $F_{2}(B 2 \times B 35)$ vs. $\mathrm{L}_{3}(\mathrm{~V} 1 \times \mathrm{V} 5)$

Test of linkage

1. $\mathrm{B}_{1}(\mathrm{~V} 2 \times \mathrm{V} 12)$ vs. $\mathrm{L}_{1}(\mathrm{~V} 2 \times \mathrm{V} 12)$

2. $B_{2}(\mathrm{~V} 2 \times V 12)$ vs. $L_{2}(\mathrm{~V} 2 \times V 12)$

3. $\mathrm{B}_{1}(\mathrm{D} 10 \times \mathrm{D} 17)$ vs. $\mathrm{L}_{1}(\mathrm{D} 10 \times \mathrm{D} 17)$

4. $B_{2}(D 10 \times D 17)$ vs. $L_{2}(D 10 \times D 17)$

5. $F_{2}(\mathrm{~V} 2 \times \mathrm{V} 12)$ vs. $\mathrm{F}_{2}(\mathrm{D} 10 \times \mathrm{D} 17)$ vs. $\mathrm{L}_{3}(\mathrm{~V} 2 \times \mathrm{V} 12)$ vs. $\mathrm{L}_{3}(\mathrm{D} 10 \times \mathrm{D} 17)$

See table 4 for probability levels.

$\begin{array}{ccc} & \mathrm{V} 1 \times \mathrm{V} 5 \text { and B2 } & \mathrm{B} 35 \text { crosses } \\ \text { df } & \text { Final height } & \text { Flowering time } \\ & \chi_{(\mathrm{df})}^{2} & \chi_{(\mathrm{df})}^{2} \\ 1 & 3.08^{\mathrm{NS}} & 8.75^{* *} \\ 1 & 0.00^{\mathrm{NS}} & 5.80^{*} \\ & & \\ 2 & 4.43^{\mathrm{NS}} & 3.62^{\mathrm{NS}}\end{array}$

\begin{tabular}{|c|c|c|}
\hline \multicolumn{3}{|c|}{$\mathrm{V} 2 \times \mathrm{V} 12$ and $\mathrm{D} 10 \times \mathrm{D} 17$ crosses } \\
\hline & $\begin{array}{c}\text { Final height } \\
\chi_{\text {(df) }}^{2}\end{array}$ & $\begin{array}{l}\text { Flowering time } \\
\chi_{(\mathrm{df})}^{2}\end{array}$ \\
\hline 1 & $2 \cdot 36^{\mathrm{NS}}$ & $0 \cdot 00^{\mathrm{NS}}$ \\
\hline & $0 \cdot 00^{\mathrm{NS}}$ & $1 \cdot 99^{\text {NS }}$ \\
\hline & $4.97^{*}$ & $28 \cdot 86^{* * *}$ \\
\hline & $0 \cdot 57^{\mathrm{NS}}$ & $13 \cdot 44 * * *$ \\
\hline & $1 \cdot 71^{\mathrm{NS}}$ & $10 \cdot 59^{*}$ \\
\hline
\end{tabular}

As there was no evidence of non-allelic interaction for final height in the V1 $\times$ V 5 and $\mathrm{B} 2 \times \mathrm{B} 35$ pair of crosses there is, as expected, no evidence of linkage of interacting genes. On the other hand, flowering time in these crosses where there was clear evidence of non-allelic interactions shows a significant linkage disequilibrium among the interacting genes, which confirms the results of earlier experiments (Jinks and Perkins, 1969).

Although both characters in the V $2 \times \mathrm{V} 12$ and D10 $\times$ D 17 pair of crosses showed highly significant non-allelic interactions there is little evidence of a linkage disequilibrium among the interacting genes for final height but quite strong evidence for flowering time (table 5). The latter, of course, agrees with the model fitting to the basic generations (table 4).

\section{(ii) Within family variances}

$V_{1 F 2}$ and $\left(V_{1 B 1}+V_{1 B 2}\right)$ for corresponding association and dispersion pairs of crosses have been compared by iterative weighted least squares model fitting procedures which lead to a $\chi^{2}$ test of goodness of fit (Mather and Jinks, 1971). The comparisons have been carried out independently 
for the $F_{2}$ and backcross variances using a technique which we will illustrate for $V_{1 F 2}$ in the $\mathrm{V} 1 \times \mathrm{V} 5$ and $\mathrm{B} 2 \times \mathrm{B} 35$ pair of crosses.

A single model was fitted to the two estimates of $V_{1 F 2}$ and the estimates of the environmental component of variation $E$ obtained as $\frac{1}{4} V_{P 1}+\frac{1}{4} V_{P 2}+$ $\frac{1}{2} V_{F 1}$ for the $\mathrm{V} 1 \times \mathrm{V} 5$ and $\mathrm{B} 2 \times \mathrm{B} 35$ crosses (Mather and Jinks, 1971). To test specifically the hypothesis that the genetical component $(G)$ of the two estimates of $V_{1 F 2}$ is the same, the following three parameter model was fitted to the four estimates.

$$
\begin{aligned}
V_{1 F 2}(\mathrm{~V} 1 \times \mathrm{V} 5) & =G+E^{\prime} \\
V_{1 F 2}(\mathrm{~B} 2 \times \mathrm{B} 35) & =G+E^{\prime \prime} \\
\frac{1}{4} V_{P 1}+\frac{1}{4} V_{P 2}+\frac{1}{2} V_{F 1}(\mathrm{~V} 1 \times \mathrm{V} 5) & =E^{\prime} \\
\frac{1}{4} V_{P 1}+\frac{1}{4} V_{P 2}+\frac{1}{2} V_{F 1}(\mathrm{~B} 2 \times \mathrm{B} 35) & =E^{\prime \prime}
\end{aligned}
$$

The $\chi_{(1)}^{2}$ testing the goodness of fit of this model will be significant only when $G$ differs significantly between the dispersion and association pairs of crosses.

The $\chi^{2}$ obtained on fitting such a model to the observed variances in table 3 are presented in table 6 along with the observed values of the environmental component $E$.

TABLE 6

Genetic components $\left(V_{1 F 2}\right)$ and $\left(V_{1 B 1}+V_{1 B 2}\right)$ and the estimate of environmental component

\begin{tabular}{|c|c|c|c|c|c|c|}
\hline Component & $\begin{array}{l}\mathrm{V} 1 \times \mathrm{V} 5 \\
\text { cross }\end{array}$ & $\begin{array}{c}\mathrm{B} 2 \times \mathrm{B} 35 \\
\text { cross }\end{array}$ & $x_{(1)}^{2}$ & $\begin{array}{c}\mathrm{V} 2 \times \mathrm{V} 12 \\
\text { cross }\end{array}$ & $\begin{array}{c}\mathrm{D} 10 \times \mathrm{D} 17 \\
\text { cross }\end{array}$ & $x_{(1)}^{2}$ \\
\hline \multicolumn{7}{|c|}{ Final height } \\
\hline $\begin{array}{l}V_{1 F 2} \\
V_{1 B 1}+V_{1 B 2} \\
E\end{array}$ & $\begin{array}{r}53 \cdot 18 \\
68 \cdot 08 \\
213.86\end{array}$ & $\begin{array}{r}49 \cdot 85 \\
74 \cdot 11 \\
225 \cdot 33\end{array}$ & $\begin{array}{l}0.01^{\mathrm{NS}} \\
0.01^{\mathrm{NS}}\end{array}$ & $\begin{array}{l}407 \cdot 86 \\
450 \cdot 86 \\
156 \cdot 19\end{array}$ & $\begin{array}{r}254.83 \\
92.09 \\
197.54\end{array}$ & $\begin{array}{l}5 \cdot 92^{*} \\
7 \cdot 41^{* *}\end{array}$ \\
\hline \multicolumn{7}{|c|}{ Flowering time } \\
\hline $\begin{array}{l}V_{1 F 2} \\
V_{1 B 1}+V_{1 B 2} \\
E\end{array}$ & $\begin{array}{l}15 \cdot 76 \\
14 \cdot 27 \\
24 \cdot 43\end{array}$ & $\begin{array}{r}5 \cdot 38 \\
6 \cdot 11 \\
27 \cdot 90\end{array}$ & $\begin{array}{l}3 \cdot 50 \dagger \\
4 \cdot 54^{*}\end{array}$ & $\begin{array}{l}48 \cdot 35 \\
43 \cdot 83 \\
16 \cdot 98\end{array}$ & $\begin{array}{l}26 \cdot 21 \\
36 \cdot 37 \\
12 \cdot 58\end{array}$ & $\begin{array}{l}4.98^{*} \\
0.49^{\mathrm{NS}}\end{array}$ \\
\hline
\end{tabular}
$E$ of the $V 1 \times V 5, B 2 \times B 35, V 2 \times V 12$ and $D 10 \times D 17$ crosses and the tests of goodness of fit of a model which assumes the same genetic component for the corresponding association and dispersion crosses

For probability levels see table 4 .

$\dagger P=0.06$.

The results can be interpreted by reference to the categorisation in section 2 ((i) to (iii)). For final height in the V1 $\times$ V5 and B2 $\times$ B35 pair of crosses the genetical components of $V_{1 F 2}$ and $\left(V_{1 B 1}+V_{1 B 2}\right)$ do not differ significantly so that there is no evidence for either non-allelic interaction or a linkage disequilibrium. For flowering time in the same crosses $V_{1 F 2}$ shows a marginally significant difference and $\left(V_{1 B 1}+V_{1 B 2}\right)$ a significant difference. Furthermore, the genetical components are larger for the dispersion than for the association cross and therefore the cause can only be a linkage disequilibrium of interacting genes. This same pattern also applies to flowering time in the V2 $\times$ V12 and D10 $\times$ D17 pair of crosses and hence there is a linkage disequilibrium of interacting genes. For final height in 
the same crosses the genetical components of both $V_{1 F 2}$ and $\left(V_{1 B 1}+V_{1 B 2}\right)$ differ significantly and they are markedly larger for the dispersion than for the association cross. But again the only explanation compatible with this pattern is a linkage disequilibrium of interacting genes.

\section{Discussion}

The expected variances in table 1 show that non-allelic interaction, linkage disequilibrium of non interacting genes and linkage disequilibrium of interacting genes can be individually identified by comparison of the within family variances of the basic generations of matched pairs of association and dispersion crosses. Comparison of these variances in two sets of matched association and dispersion crosses between pure breeding varieties of Nicotiana rustica and between highly inbred selections derived from them confirm these theoretical expectations. Indeed for final height the comparison of the within family variances of the basic generations was as informative as the most sensitive analysis of the means of the families of the basic generations and of a triple test cross. But whereas an analysis of means can detect only contributions to the variation that have a net directional effect, the comparison of variances is equally sensitive to ambidirectional effects.

For flowering time the comparison of variances is less conclusive than the analysis of means in one pair of association and dispersion crosses although there is no disagreement between them. This is almost certainly due to the small difference in the degree of association/dispersion (section 3 ) between the association and dispersion pair of crosses rather than to an inherent lower sensitivity of the variances to the presence of non-allelic interaction or a linkage disequilibrium.

Provided, therefore, that we have available the basic generations of a matched pair of crosses differing markedly in their degrees of association/dispersion for the characters of interest, a simple experimental design of modest dimensions will allow the detection of the most complex contributors to variation that have been encountered in biometrical genetical analyses (Mather and Jinks, 1982).

\section{REFERENCES}

JAYASEKARA, N. E. M., AND JINKS, J. L. 1976. Effect of gene dispersion on estimates of components of generation means and variances. Heredity, 36, 31-40.

JINKS, J. L. 1954. The analysis of continuous variation in a diallel cross of Nicotiana rustica varieties. Genetics, 39, 767-788.

JINKS, J. L. 1956. The $\mathrm{F}_{2}$ and backcross generations from a set of diallel crosses. Heredity, $10,1-30$.

JINKS, J. L. 1978. Unambiguous test for linkage of genes displaying non-allelic interactions for a metrical trait. Heredity, 40, 171-173.

JINKS, J. L., JAYASEKARA, N. E. M., AND BOUGHEY, H. 1977. Joint selection for both extremes of mean performance and of sensitivity to a macro-environmental variable. II. Single seed descent. Heredity, 39, 345-355.

JINKS, J. L., AND JONES, R. M. 1958. Estimation of the components of heterosis. Genetics, 43, 233-234.

JINKS, J. L., AND PERKINS, J. M. 1969. The detection of linked epistatic genes for a metrical trait. Heredity, 24, 465-475. 
JINKS, J. L., AND PERKINS, J. M. 1972. Predicting the range of inbred lines. Heredity, 28, 399-403.

MATHER, K. 1949. Biometrical Genetics, First edition. Methuen, London.

MATHER, K. 1967. Complementary and duplicate gene interactions in biometrical genetics. Heredity, 22, 97-103.

MATHER, K., AND JINKS, J. L. 1971. Biometrical Genetics, Second edition, Chapman and Hall, London.

MATHER, K., AND JINKS, J. L. 1982. Biometrical Genetics, Third edition, Chapman and Hall, London.

OPSAHL, B. 1956. The discrimination of interaction and linkage in continuous variation. Biometrics, 12, 415-432.

PERKINS, J. M., AND IINKS, J. L. 1970. Detection and estimation of genotype-environmental, linkage and epistatic components of variation for a metrical trait. Heredity, 25, 157-177. POONI, H. S., AND JINKS, J. L. 1981. The true nature of the non-allelic interactions in Nicotiana rustica revealed by association crosses. Heredity, 47, 253-258.

POONI, H. S., JINKS, J. L., AND JAY ASEKARA, N. E. M. 1978. An investigation of gene action and genotype $\times$ environmental interaction in two crosses of Nicotiana rustica by triple test cross and inbred line analysis. Heredity, 41, 83-92. 